The position of the Smalls Light, it may be observed, is such that it offers special advantages for the application of the proposed method. A ship rounding the Land's End, bound for the Irish Channel, after passing the Longships Light, has a run of about I30 miles for the Tuskar Light, and towards the end the tidal currents set across the mouth of the Channel with considerable velocity. In such a case observations of the Smalls Light, should it become visible on the starboard bow, would be of considerable service in checking the course laid for the Tuskar.

H. B. G.

\title{
Late Keltic Remains from a Mendip Cave.
}

$\mathrm{A}^{\mathrm{N}}$ $\mathrm{N}$ important series of Late Keltic objects has been brought to light by members of the Speleological Society of the University of Bristol in the course of investigations in a cave in the Mendips. The cave was first discovered in September, 1919, and the work of exploration, which has been done on most systematic lines, has been carried on throughout the past year. The finds, which were described by Mr. L. S. Palmer at a recent meeting of the Royal Anthropological Institute, included objects of worked bone and stone, bronze hubs and bands of chariot-wheels, bronze bracelets and finger-rings, iron slave shackles, an iron kev, spindle whorls, and similar objects. A considerable amount of pottery was also found which in design and technique was comparable to that found in most Late Keltic settlements. It does not, however, exhibit the characteristic curvilinear motives, the chief decorative feature being in the form of an inverted $\mathrm{C}$. Only three human bones were discovered. There was a large number of bones of domestic and wild animals. A peculiar feature of the discovery is that all these objects were found either on the surface of the floor of the cave or in a thin band of mud which constituted the uppermost layer. There was no evidence of earlier occupation or any trace of Roman occupation. These facts, taken in conjunction with evidence which points to occupation of the cave having taken place in abnormal circum- stances, would suggest that the cavern was used as a temporary refuge.

The discovery is of great importance in connection with the question of the relations which subsisted between this country and the Continent during the Iron age. The character of the finds, and in particular the close affinity exhibited by the pottery to that of Brittany, pointed, in Mr. Palmer's opinion, to the site having been occupied by a tribe of the Brythons who migrated to this country from the north of France. The same people built Glastonbury Lake Village, and are known to have inhabited Wookey Hole, Worlebury Camp, and some hut circles on Brean Down, all of which are within a few miles of this cave. In support of his view Mr. Palmer pointed out that the hill forts in this area all face in a northerly direction, which would suggest that they were the van of a wave of immigration from the south. On the other hand, as Prof. Keith pointed out, the type of skull usually associated with this type of culture in the west of England differs essentially from the Breton skull, and the affinity between the pottery of this area and that of Brittany may well be the result of commerce rather than of immigration. It may be hoped that the further exploration of the site which is to be carried on during the coming year may produce fresh evidence to throw light upon a period concerning which our present knowledge is all too scanty.

\section{Physiology at the British Association.}

$\mathrm{O}$ Tuesday, August 24, the Section of Physiology held a joint meeting with the Sub-Section of Psychology. At this joint sitting Dr. Rivers opened a discussion on the desirability of establishing a separate Section of Psychology. The address of the chairman of the Sub-Section (Dr. C. S. Myers) was on almost the same subject. Dr. Rivers gave an outline of the history of psychology in relation to the British Association, and showed that there had been a great increase in the number of papers on psychological subjects contributed to the Association. He pointed out that psychology had developed methods and problems of its own. At the end of the discussion Dr. Rivers moved a resolution: "That this meeting of the Section approves of the constitution of a separate Section of Psychology." This resolution was passed nem. con., and it was referred to the committee of the Section.

At the same joint meeting Miss M. Smith and Dr. W. McDougall read a paper on "The Effect of Drugs on Fatigue." Fatigue was induced by sitting up all night for three successive nights, and the effect was studied by means of dotting circles on a moving tape and by memory tests with related words. The first effect of fatigue was to increase the efficiency, but after the first few days the efficiency showed a marked decline and remained below the normal for from sixteen to nineteen days. This showed that the effect of the loss of sleep extended for a considerable period after the loss of sleep had occurred. The NO. 2669 , VOL. IO6] drugs were given disguised so that they could not be recognised. Most of the experiments were with alcohol or opium. The action of alcohol was to decrease the efficiency except during the period of recovery, when a stage occurred in which alcohol caused the efficiency to approach the normal nonfatigued value. Opium caused an increase in efficiency which was more marked in the recovery stage. When the dotting and memory tests were carried out together alcohol caused them to vary together, and the subjective effect was not unpleasant, but opium caused one process to improve at the expense of the other, and the subjective effect was distinctly unpleasant.

On Friday, August 27, the Section of Physiology met the Section of Botany to discuss "Biochemistry and Systematic Relationship." An account of this discussion appears in the article upon the proceedings of the Section of Botany (p. 550).

Several of the meetings of the Section were held in the new buildings for the department of physiology, when the members of the Section had the privilege of inspecting the excellent accommodation for the department. At one of these meetings Prof. Haycraft demonstrated a new pulse recorder, which consists of a mirror resting on the artery, the records being made by photographing the movement of a spot of light reflected from the mirror.

Dr. 'T. Lewis read a paper on "The Relation of Physiology to Medicine." This was largely a plea 
for the development of the subject of human physiology. He pointed out the importance of a knowledge of physiology for rational medicine, but contended that it would be of greater value if more use were made of the human subject for illustrating the facts of physiology. The use of methods of examination applicable to the human subject should be extended, but, of course, the methods must be controlled by experiments on animals. Dr. Lewis finished his paper by appealing to the citizens of South Wales for an endowment for the department of physiology. As a graduate from South Wales, he felt the handicap due to lack of accommodation and of equipment; now that a good building had been provided he hoped that sufficient money would be forthcoming for its equipment and upkeep.

As a good example of the way in which animal experiments must be used to elucidate the physiology of the human subject Dr. Lewis's paper on "Auricular Flutter" may be quoted. This was a description of experiments on the heart of the dog. The time-relations of electrical changes in the auricle were traced, and they were found to differ from those of the auricle beating in its natural way. 'The evidence from the time-relations of the electrical changes points to a wave of contraction passing round the superior and inferior venæ cavæ. The normal beat consists of a contraction wave which spreads over the whole auricle, but in auricular flutter the wave travels down one side of the auricle round the inferior vena cava, and returns by the other side of the auricle to the superior vena cava. This establishes a circus movement which continues indefinitely. The wave of excitation reaches each part of the auricle at a sufficient interval after the previous contraction to fall outside the refractory period; hence the series of quickly following circus movements. The normal contraction ends because the wave of contraction spreads fan-like over the whole auricle, when it reaches the limits of the auricle: it ceases because the wave of excitation is dammed by the refractory period of the contracting auricle.

Miss E. Bedale, in collaboration with others, read a paper on "The Energy Requirements of Schoolchildren." The measurement of energy was attempted in two ways. The first consisted in obtaining diet-sheets prepared by the pupils on which they recorded the weighed amounts of the various food materials eaten. These diets were evaluated by analytical data, and the energy-value of the diet was obtained in that way. The second method was to measure the energy expenditure by means of the respiratory exchange. The basal metabolism was measured during sleep. Measurements of the respiratory exchange were made during various forms of activity and the daily expenditure was estimated by a calculation involving the amount of time occupied in the difterent forms of activity. The two energy values did not agree, the intake of energy being greater than the expenditure. It was left an open question as to how much of the lack of agreement was due to errors in computing the energy output in the various forms of activity during the day.

Prof. Waller gave some figures on an allied subject in which he measured the energy expenditure by the output of carbon dioxide. He contrasted a man in training with an untrained man running the same distance at the same speed. Assuming that the basal metabolism of the two men was the same, the untrained man expended double the amount of energy in doing the same work.

Prof. Herring recorded measurements showing the effect of pregnancy on the various organs of the white rat. The animals were from a standard litter, and kept under identical conditions except for the occurrence of pregnancy in some of them. Most of the organs showed a slight decrease in weight; the only ones that showed an increase in weight were the liver and the adrenals. The increase in the former shows the great importance of metabolism during pregnancy. The increase in the latter is probably in the cortex, and not in the medulla.

Dr. Edridge-Green read a paper on "The Prevention of Myopia," in which he stated that the exciting cause of myopia is an increase in intra-ocular pressure. Games such as cricket, football, golf, etc., do not cause myopia, but severe strains such as lifting heavy weights, especially with the eyes pointing downwards, should be avoided.

Prof. Waller recorded some further observations on "The Emotive Response of the Human Subject." The response is usually confined to the hand and foot, but a few individuals show it on the forearm and leg. The reaction appears first on the hand $\left(2^{\prime \prime}\right)$ and then on the foot $\left(3^{\prime \prime}\right)$. If it occurs elsewhere it is delayed as long on the arm as on the foot $\left(3^{\prime \prime}\right)$, and shows a longer latent interval on the leg (4").

Prof. Waller presented the report of the Committee on Electromotive Phenomena in Plants. The zone of growth in iris is at the base of the leaf, and in anemone at the apex of the plant. When an induction shock is passed through an active growing tissue the resultant electrical change is always from the more active to the less active portion in the planttissue, no matter in which direction the stimulating current is passed. In dead tissues the current produced after stimulation is small, and always in the direction of polarisation.

\section{Botany at the British Association.}

THE diversified character of modern botany was well exemplified in the programme of the Cardiff meeting, and the rapprochement of the sciences was evidenced by the three joint discussions in which the Section took part. Joint sittings have become an important feature of recent years, and in this reflect the tendency of modern research to overstep the necessarily arbitrary boundaries of the socalled sciences and to combine with other workers on the border-line problems.

Thus it is not surprising to find botanists cooperating with zoologists and geologists to consider whether Mendelian work and palæontological evidence show as yet any sign of giving mutual support to the conclusions derived from each line independently.

The joint discussion with the physiologists and chemists entitled "Biochemistry and Systematic Relationships," presided over by Miss Saunders, president of the Botany Section, aimed at con- sidering whether the present state of knowledge indicates any definite ratio between biochemical constitution and morphological expression--that is to say, does biochemical investigation show a chemical relationship in the forms which have long been grouped together on morphological grounds? The discussion was introduced by a paper by the Hon. Mrs. Onslow, wherein the possibility of expressing reproductive and vegetative characters in chemical terms was explored; lines of plant-metabolism were considered and suggestions made as to correlations between the evolution of the families of flowering plants and the presence of oxygenases, and the distribution of anthocyan pigments and of flavones was discussed. The papers and open discussion which followed indicated the importance of the new line of work, inasmuch as a considerable correspondence of chemical and morphological relationship had been established, but laid stress also on the necessity for extreme carefulness in its application in view of the 